\title{
Analysis of the performance of $\mathrm{Nb}(2) \mathrm{O} 5$-doped SiO2-based MIM devices for memory and neural computation applications
}

Ossorio, O. G.

$2021-12$

Ossorio , O G , Vinuesa , G , Garcia , H , Sahelices , B , Duenas , S , Castan , H , Ritala , M , Leskela , M , Kemell , M \& Kukli , K 2021 , ' Analysis of the performance of $\mathrm{Nb}$ (2)O5-doped SiO2-based MIM devices for memory and neural computation applications ' , Solid-State Electronics , vol. 186 , 108114 . https://doi.org/10.1016/j.sse.2021.108114

http://hdl.handle.net/10138/336114

https://doi.org/10.1016/j.sse.2021.108114

publishedVersion

Downloaded from Helda, University of Helsinki institutional repository.

This is an electronic reprint of the original article.

This reprint may differ from the original in pagination and typographic detail.

Please cite the original version. 


\title{
Analysis of the performance of $\mathrm{Nb}_{2} \mathrm{O}_{5}$-doped $\mathrm{SiO}_{2}$-based MIM devices for memory and neural computation applications
}

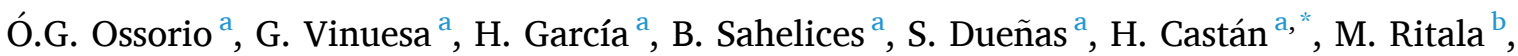 \\ M. Leskela ${ }^{\text {b }}$, M. Kemell ${ }^{\text {b }}$, K. Kukli ${ }^{\mathrm{c}}$ \\ a Department of Electronics, University of Valladolid, Paseo de Belén 15, Valladolid E-47011, Spain \\ ${ }^{\mathrm{b}}$ Department of Chemistry, University of Helsinki, P.O.Box 55, Helsinki FI-00014, Finland \\ ${ }^{\mathrm{c}}$ Institute of Physics, University of Tartu, W. Ostwald 1, Tartu 50411, Estonia
}

\section{A R T I C L E I N F O}

\section{Keywords:}

RRAM

NVM

MIM stack

Niobium oxide

Silicon oxide

\begin{abstract}
A B S T R A C T
Since two decades ago, research on resistive memories has continuosly grown, gathering relevance through the variety of different technologies that fit into the non-volatile memories' area. In this study, we discuss the performance and electrical characteristics of RRAM cells constituted by MIM stacks with dielectric formed by $\mathrm{Nb}_{2} \mathrm{O}_{5}$-doped $\mathrm{SiO}_{2}$. We report experimental results that show a clear improvement in the resistive behavior of the devices and an excellent analogical control of the intermediate levels between high-resistance and low-resistance states.
\end{abstract}

\section{Introduction}

Resistive random access memories (RRAM) are of increasing interest, and they show fast write and erase operations, small cell size, good cyclic endurance and low working voltage. Due to the multi-valence nature of transition metals, their oxides work well as resistive switching layers, and are hence widely used in this application. $\mathrm{SiO}_{2}$ layers were used as resistive switching media in 3D crossbar arrays patterned on conductive wafers covered by chemically oxidized Si [1]. RRAM characteristics simulating synaptic behavior were also aimed and described in $\mathrm{SiO}_{2}$ media formed on thermally oxidized $\mathrm{Si}$ [2], or sputtered on platinum [3]. RRAM behavior has been analyzed also in another work on $\mathrm{SiO}_{2}$ films reactively sputtered on platinum [4]. Notably, $\mathrm{SiO}_{2}$ contact barrier layers have been applied in sputtered stacks between Pt electrodes and nonstoichiometric $\mathrm{Ta}_{2} \mathrm{O}_{5-\mathrm{x}} / \mathrm{TaO}_{2-\mathrm{x}}$ charge carrier source layers [5], where the $\mathrm{SiO}_{2}$ layer assisted in confining the conduction channels and formation of filaments in the resistive switching regime.

While $\mathrm{Ta}_{2} \mathrm{O}_{5}$ has quite widely been used as RRAM medium, $\mathrm{Nb}_{2} \mathrm{O}_{5}$, which is an oxide closely related to $\mathrm{Ta}_{2} \mathrm{O}_{5}$ in terms of the chemical and physical properties, has been scarcely explored in the development of memristive devices. Nonetheless, $\mathrm{Nb}_{2} \mathrm{O}_{5} / \mathrm{NbO}_{2}$-based thin stacked layers have earlier been engineered for 3D RRAM applications [6]. In another and more recent paper, chemical nature of $\mathrm{NbO}_{\mathrm{x}}$ films sputtered on Pt electrodes, affecting switching characteristics, was studied again [7]. Moreover, devices based on niobium oxides were proposed as prospective for neural computation, emulating the computational capability of a nerve system [8].

Remarkably, $\mathrm{Nb}_{2} \mathrm{O}_{5}$ films as resistive switching media have been grown by atomic layer deposition (ALD), as well, using either $\mathrm{Nb}$ $\left(\mathrm{OCH}_{2} \mathrm{CH}_{3}\right)_{5}$ and $\mathrm{H}_{2} \mathrm{O}$ [9] or $\mathrm{C}_{13} \mathrm{H}_{33} \mathrm{~N}_{4} \mathrm{Nb}$ and $\mathrm{O}_{2}$ plasma [10] processes on Pt electrode substrates. In the latter study, $\mathrm{TiO}_{2}$ film was deposited between $\mathrm{Nb}_{2} \mathrm{O}_{5}$ layers to assist in the creation of low-power forming-free RRAM device, indicating the adequation of multilayer structure.

In a previous study [11], $\mathrm{Nb}_{2} \mathrm{O}_{5}-\mathrm{SiO}_{2}$ multilayers and mixed films were deposited on TiN electrode substrates by ALD using niobium pentaethoxide, hexakis(ethylamino) disilane, and ozone as precursors, and their ability to perform as resistive switching media in as-deposited state was examined. The conduction currents in single, non-mixed, $\mathrm{SiO}_{2}$ and $\mathrm{Nb}_{2} \mathrm{O}_{5}$ films tended to remain too high to enable reliable switching between high and low resistance states. In the $\mathrm{Nb}_{2} \mathrm{O}_{5}-\mathrm{SiO}_{2}$ nanolaminates, however, after tuning the relative content of $\mathrm{Nb}_{\text {in }} \mathrm{SiO}_{2}$ based films, better defined current-voltage switching loops could be recorded in the films deposited using $\mathrm{Nb}_{2} \mathrm{O}_{5}: \mathrm{SiO}_{2}$ cycle ratio of $1: 5$, providing $\mathrm{Nb}$ : Si cation ratio of 0.13 .

In the present study, $\mathrm{Nb}_{2} \mathrm{O}_{5}-\mathrm{SiO}_{2}$ mixed films with $\mathrm{Si}$ content approximately tenfold higher than that of $\mathrm{Nb}$ were examined in conventional resistive switching and small-signal regimes, in order to map

\footnotetext{
* Corresponding author.

E-mail address: helena@ele.uva.es (H. Castán).
} 


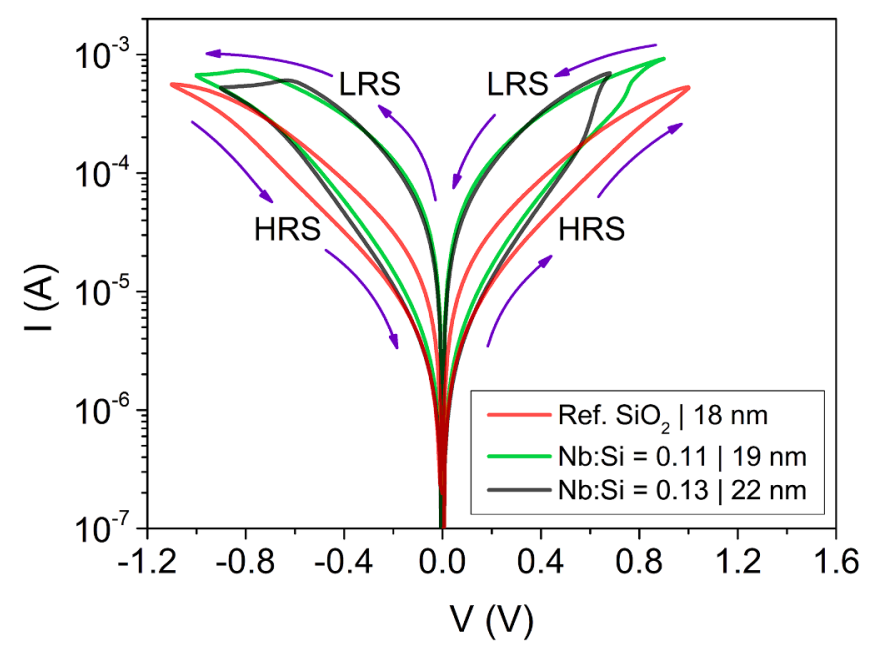

Fig. 1. Mean values of 20 current-voltage cycles for 3 dielectric films with different $\mathrm{Nb}: \mathrm{Si}$ ratios and grown to the thicknesses indicated by labels.

the conductivity and capacitance memory states against amplitudes of programming voltage. Incremental and accumulative measurements were performed in order to study the effects of intermediate charging between consecutive Set and Reset events, i.e., writing and erasing bits, respectively.

\section{Experimental details}

The dielectric films composed of $\mathrm{SiO}_{2}$ and $\mathrm{Nb}_{2} \mathrm{O}_{5}$ were grown by ALD from $\mathrm{Si}_{2}(\mathrm{NHEt})_{6}, \mathrm{Nb}\left(\mathrm{OC}_{2} \mathrm{H}_{5}\right)_{5}$, and $\mathrm{O}_{3}$ at $300{ }^{\circ} \mathrm{C}$ in a flow-type hot-wall ALD reactor F120 (ASM Microchemistry, Ltd) to thicknesses around 20 $\mathrm{nm}$. The cycle times used for both $\mathrm{SiO}_{2}$ and $\mathrm{Nb}_{2} \mathrm{O}_{5}$ constituent layers were $0.5-0.5-2.0-0.5 \mathrm{~s}$, denoting the sequence $\mathrm{Si}$ or $\mathrm{Nb}$ precursor pulse purge - $\mathrm{O}_{3}$ pulse - purge. Electrically conducting substrates were composed of (100) oriented silicon with a resistivity of 0.014-0.020 $\Omega$. $\mathrm{cm}$, i.e. boron-doped $\mathrm{Si}$ to the concentrations ranging from $5 \times 10^{18}$ to 1 $\times 10^{19} \mathrm{~cm}^{-3}$, coated with $10 \mathrm{~nm}$ thick crystalline titanium nitride layer. Energy dispersive X-ray spectrometry (EDX) was used for the measurements of the film thicknesses as well as relative niobium and silicon contents in the films by a Hitachi S-4800 scanning electron microscope equipped with an Oxford INCA 350 EDX spectrometer. The atomic ratios of niobium to silicon ranged from 0 to 0.13 . The films were amorphous in the as-deposited state [11]. The structure of the stacks subjected to the measurements was $\mathrm{Al} / \mathrm{Ti} / \mathrm{SiO}_{2}: \mathrm{Nb}_{2} \mathrm{O}_{5} / \mathrm{TiN} / \mathrm{Si}$, where the top electrodes were made by electron beam evaporation through a shadow mask. The devices under test had three different areas: $0.204 \mathrm{~mm}^{2}, 0.052 \mathrm{~mm}^{2}$ and $0.002 \mathrm{~mm}^{2}$. Keithley 4200 -SCS meter was used for the electrical characterization of the device stacks. Small signal measurements were carried out by applying a $30 \mathrm{mV}$ signal at $100 \mathrm{kHz}$ over the DC voltage.

\section{Results and discussion}

The influence of adding $\mathrm{Nb}_{2} \mathrm{O}_{5}$ to $\mathrm{SiO}_{2}$ in terms of power consumption, width of the resistance window and precise control of the intermediate states was assessed. We performed a full comparison among three samples: the reference unmixed $\mathrm{SiO}_{2}$ film $(18 \mathrm{~nm})$ and films with $\mathrm{Nb}: \mathrm{Si}$ ratios of $0.11(19 \mathrm{~nm})$ and $0.13(22 \mathrm{~nm})$. In Fig. 1 current-voltage (I-V) cycles showing the switching between the high and low resistance states (HRS and LRS, respectively) are depicted. In these oxide films, the resistive switching behavior is due to the segregation of oxygen vacancies that may form a nano-filament which works as a conducting leakage path. As it is known, TiN is used as a standard electrode because it plays the role of oxygen ion reservoir, aiding the formation of oxygen vacancies which build the conductive filament in the insulator between

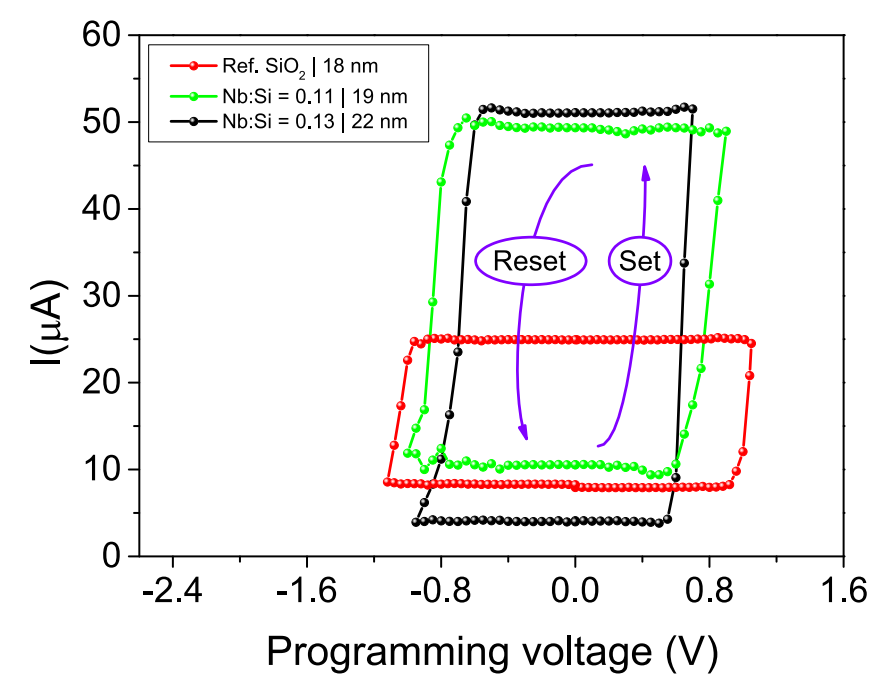

Fig. 2. Current-voltage memory maps for $\mathrm{Nb}_{2} \mathrm{O}_{5}-\mathrm{SiO}_{2}$ films with different $\mathrm{Nb}$ : $\mathrm{Si}$ atomic ratios and grown to the thicknesses indicated by labels.

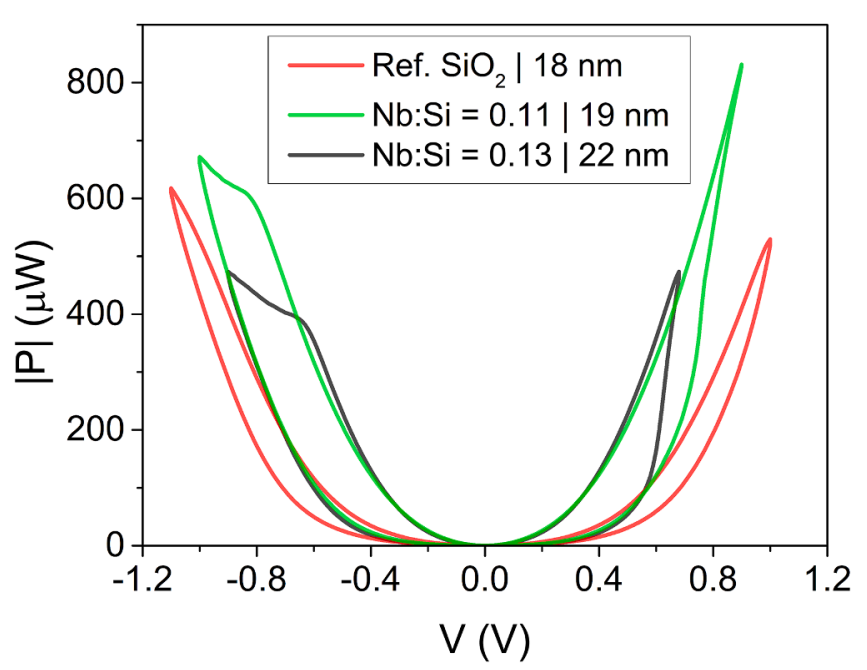

Fig. 3. Power consumed in the resistive switching media based on $\mathrm{Nb}_{2} \mathrm{O}_{5}-\mathrm{SiO}_{2}$ films with different atomic ratios and grown to the thicknesses indicated by labels. The power was calculated based on the voltage applied and current recorded in Fig. 1.

both electrodes $[12,13]$. It is shown that the narrowest functional window between the HRS and LRS was observed in the reference $\mathrm{SiO}_{2}$ device. At the same time, both $\mathrm{Nb}_{2} \mathrm{O}_{5}$-mixed devices behave quite similarly. Further, hysteretic memory maps depicted in Fig. 2 were obtained by using voltage pulses to program the device, where each programming pulse is followed by a read pulse at a fixed voltage [14]. The sequence and range of pulses completely cover the Set and Reset transitions. The read voltage was kept at $0.1 \mathrm{~V}$, in order to not affect the resistive state. One can see in Fig. 2 that in both mixed films, similar characteristic values were achieved while the reference $\mathrm{SiO}_{2}$ differed from the mixtures by a narrower window between high and low resistance levels. It is important to remark that these memory maps were not calculated by taking the average of a group of cycles, but from individual measurements. For $\mathrm{Ta}_{2} \mathrm{O}_{5}$-based devices it has been reported that the activation energy for oxygen-ion migration is much lower in Ta-rich $\mathrm{SiO}_{2}$-hosted structures in comparison with non-mixed $\mathrm{Ta}_{2} \mathrm{O}_{5}$ films [5]. As chemical and physical properties of $\mathrm{Nb}_{2} \mathrm{O}_{5}$ are similar to $\mathrm{Ta}_{2} \mathrm{O}_{5}$, we can understand that the Set current increases with the $\mathrm{Nb}$ content. In addition, the useable programming voltage range is wider for $\mathrm{SiO}_{2}$ than for the $\mathrm{Nb}_{2} \mathrm{O}_{5}-\mathrm{SiO}_{2}$. This is in a good agreement with previous studies 

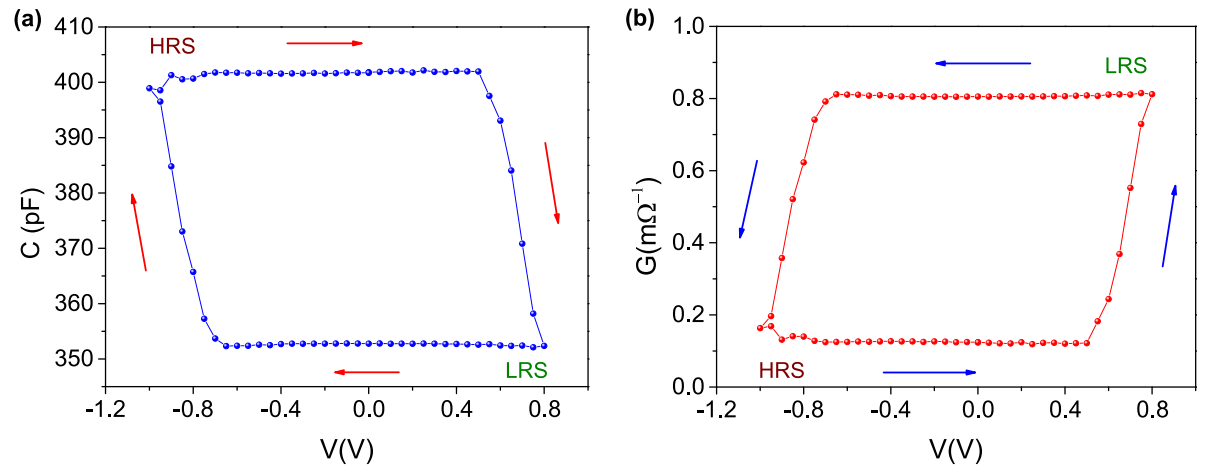

Fig. 4. Small signal memory maps corresponding to device with $\mathrm{Nb}$ :Si proportion of 0.13 . C-V map (a). G-V map (b).
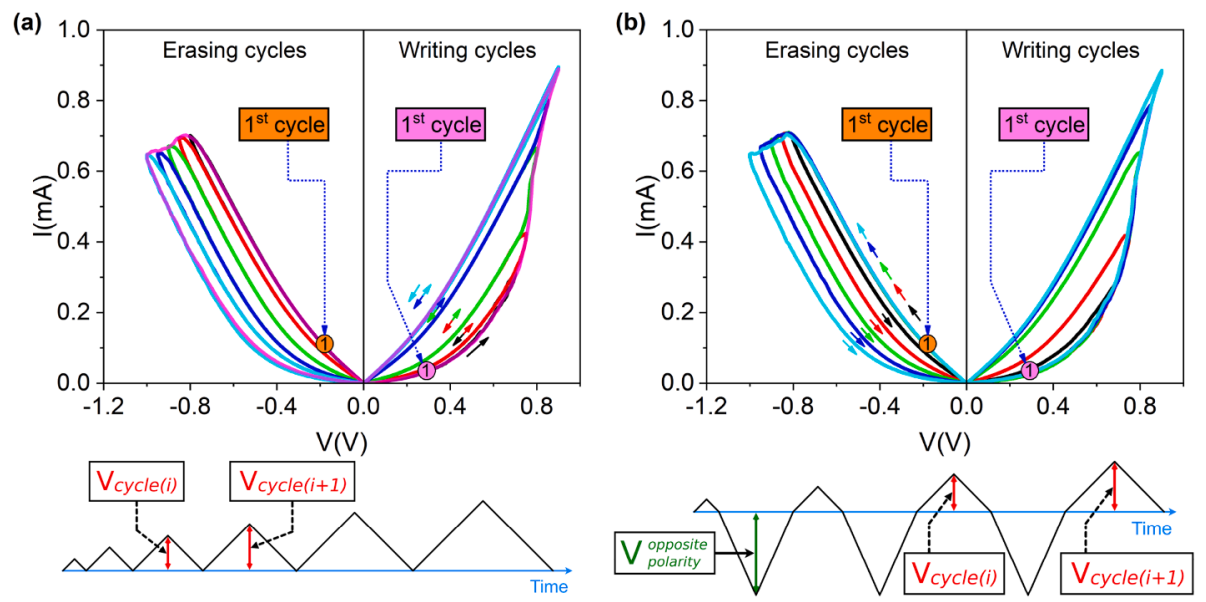

Fig. 5. Control of the intermediate states on device with $\mathrm{Nb}: \mathrm{Si}=0.11$ (I-V). Accumulative (a) and Incremental (b) experiments.

$[15,16]$ where $\mathrm{TiN}$ and $\mathrm{SiO}_{2}$ were employed as electrodes and resistive switching layers, and usually displayed high operating Set and Reset voltages, resulting in high power consumption in comparison, for example, with $\mathrm{HfO}_{\mathrm{x}}$. In Fig. 3, one can read the power consumption for each device. The film with the $\mathrm{Nb}: \mathrm{Si}$ ratio of 0.13 provided the lowest power consumption values. These results imply that the Nb:Si ratio of 0.13 in the dielectric is relatively well suited to its implementation in memory systems. Fig. 4 represents the small-signal memory maps of the mentioned sample (capacitance vs. voltage and conductance vs. voltage), which portray its excellent characteristics.

By revisiting Fig. 2, it can be seen that the Set transition is more gradual in the $19 \mathrm{~nm}$ thick sample $(\mathrm{Nb}: \mathrm{Si}=0.11)$ when compared with the other two. This detail may be useful for developing artificial synapses in neuromorphic circuits. We make this assumption even though these are large area structures. In order to adapt these structures to 1T-
1R bipolar RRAM devices, the dimensions of the filamentary channels as well as the fractional conducting areas should be taken into account [17], because both are essential parameters for determining the current level for LRS and HRS and also when estimating the ultimate packing density of the ReRAM device. As a procedure to justify the mentioned assumption, we performed some complementary measurements. The DC curves in Fig. 5 correspond to both writing and erasing cycles, which were measured in two distinct ways. Accumulative (Fig. 5a) current-voltage measurements were performed by applying the first and only cycle under the voltage polarity opposite to that in the following consecutive measurements (in order to assure that the device starts from a full HRS/LRS), continuing with voltage sweeps to maxima what were increased in each subsequent cycle. As a result, every cycle was started at the current (resistivity) level predetermined by the previous one. In Fig. $5 \mathrm{~b}$ the incremental writing and erasing test measurement is
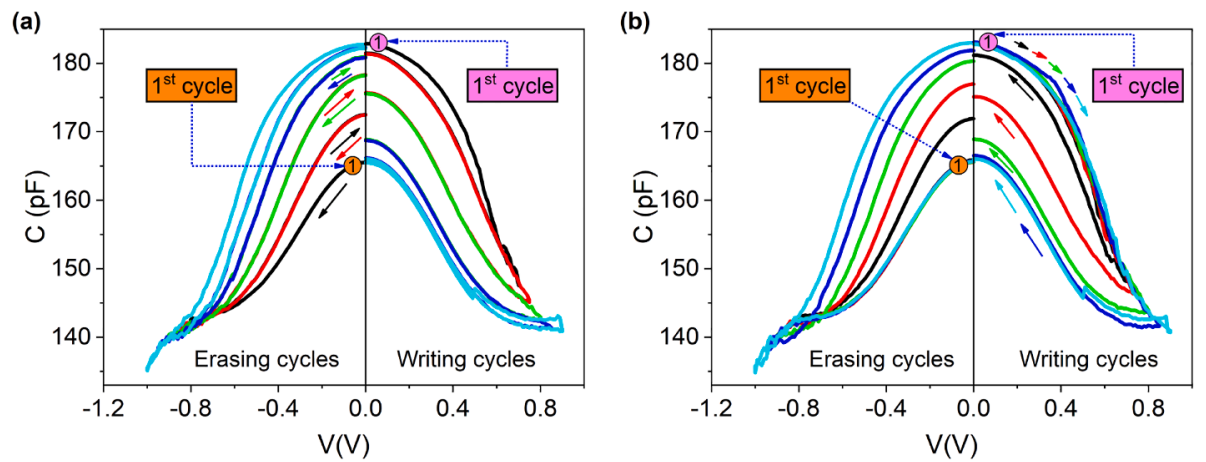

Fig. 6. Control of the intermediate states on device with $\mathrm{Nb}: \mathrm{Si}=0.11(\mathrm{G}-\mathrm{V})$. Accumulative (a) and Incremental (b) experiments. 

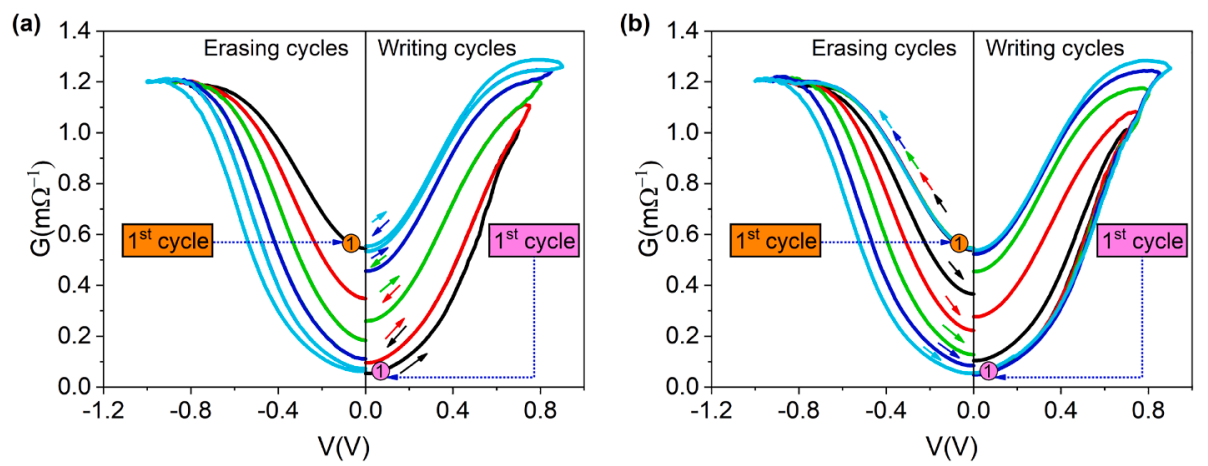

Fig. 7. Control of the intermediate states on device with $\mathrm{Nb}: \mathrm{Si}=0.11(\mathrm{G}-\mathrm{V})$. Accumulative (a) and Incremental (b) experiments.

depicted. In this case, voltage sweeps were applied to the opposite polarity after each cycle, which ensured that every cycle started at the same HRS/LRS level and reached its respective maximum current. It is important to note here the progressive Set and Reset phases in which it was not necessary to impose any current limitation (compliance). To complete the description of the measurements, Figs. 6 and 7 illustrate the small-signal writing and erasing tests, with capacitance vs. voltage curves in the former case, and conductance vs. voltage loops in the latter case. Similarly to the performance observed in the case of conventional $\mathrm{I}-\mathrm{V}$ measurements, the intermediate current (resistivity) states could become appreciably well controlled in the $\mathrm{Nb}_{2} \mathrm{O}_{5}-\mathrm{SiO}_{2}$ film with the $\mathrm{Nb}$ : $\mathrm{Si}$ atomic ratio of 0.11 .

\section{Conclusions}

The results revealed that the $\mathrm{Nb}_{2} \mathrm{O}_{5}-\mathrm{SiO}_{2}$ films can offer advanced resistive switching characteristics compared to $\mathrm{SiO}_{2}$. A film with the $\mathrm{Nb}$ : $\mathrm{Si}$ ratio of 0.13 brought appreciable results regarding power consumption and resistance window. In addition, precise control on intermediate states with another device configuration ( $\mathrm{Nb}: \mathrm{Si}$ ratio of 0.11 ) became possible by applying sequential voltage pulses at intermittent resistance values reached during the switching cycles.

\section{Declaration of Competing Interest}

The authors declare that they have no known competing financial interests or personal relationships that could have appeared to influence the work reported in this paper.

\section{Acknowledgement}

This work was funded by the Spanish Ministry of Science, Innovation and Universities grant TEC2017-84321-C4-2-R, with support of Feder funds, Finnish Centre of Excellence in Atomic Layer Deposition (284623), and Estonian Research Agency (PRG753).

\section{References}

[1] Li C, Xia Q, Springer International Publishing, Cham, 2019, pp. 791-813.

[2] Yan X, Zhou Z, Ding B, Zhao J, Zhang Y. J Mater Chem C 2017;5:2259-67.

[3] Lian X, Shen X, Fu J, Gao Z, Wan X, Liu X, Hu E, Xu J, Tong Y. Electronics 2020;9.
[4] Jiang H, Li XY, Chen R, Shao XL, Yoon JH, Hu X, Hwang CS, Zhao J. Sci Rep 2016; 6:1-11.

[5] Park G-S, Kim YB, Park SY, Li XS, Heo S, Lee M-J, Chang M, Kwon JH, Kim M, Chung U-I, et al. Nature Comm 2013;4:1-9.

[6] Kim S, Liu X, Park J, Jung S, Lee W, Woo J, et al., In: 2012 Symposium on VLSI Technology (VLSIT), 2012, pp. 155-156.

[7] Aziz J, Kim H, Rehman S, Khan MF, Kim D-K. Nanomater 2020;10.

[8] Pickett MD, Medeiros-Ribeiro G, Williams RS. Nat Mater 2013;12:114-7.

[9] Chen L, Dai Y-W, Sun Q-Q, Gu J-J, Xu Y, Ding S-J, Zhang DW. Curr Appl Phys 2011; 11:849-52.

[10] Kim KM, Zhang J, Graves C, Yang JJ, Choi BJ, Hwang CS, Li Z, Williams RS. Nano Lett 2016;16:6724-32. PMID:27661260.

[11] Kukli K, Kemell M, Heikkilä MJ, Castán H, Dueñas S, Mizohata K, Ritala M, Leskelä M. Nanotechnology 2020;31:195713.

[12] Zhang Z, Gao B, Fang Z, Wang X, Tang Y, Sohn J, Wong H-SP, Wong SS, Lo G-Q. IEEE Electron Dev Lett 2014;36:29-31.

[13] Chang T-C, Chang K-C, Tsai T-M, Chu T-J, Sze SM. Mater Today 2016;19:254-64.

[14] Castán H, Dueñas S, García H, Ossorio ÓG, Domínguez LA, Sahelices B, Miranda E, González MB, Campabadal F. J Appl Phys 2018;124:152101.

[15] Lee D, Cho E, Lee J, Jung K, Jeong M, Yamada S, Hong H, Lee K, Heo S, Ko D, et al. Appl Phys Lett 2016;108:212102.

[16] Yu M, Fang Y, Wang Z, Pan Y, Li M, Cai Y, Huang R. J Appl Phys 2016;119:195302.

[17] Singh B, Mehta B, Varandani D, Savu AV, Brugger J. Nanotechnology 2012;23: 495707.

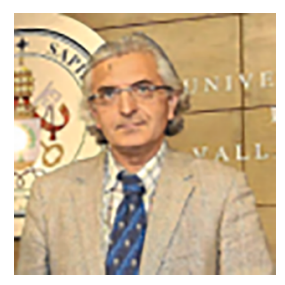

Salvador Dueñas was born in Spain in 1961. He received the Bachelor and Ph.D. degrees in Physics from the University of Valladolid, Valladolid, Spain, in 1984 and 1989, respectively. In1984, he joined the Department of Electronics, University of Valladolid, where he was an as Assistant Professor, became Associate Professor in 1987, and a Professor in 2010. His current research interests include high-k dielectrics, solar cells, defects in semiconductors, and electrical characterization of electronic materials and devices. He is author of more than 270 scientific publications. He was General Director of the Scientific Park of the University of Valladolid from 2010 to 2014, and General Manager of Research Projects on Electronic and Communication Technologies of the Science and Innovation Research Ministry of the Spanish Government from 2007 to 2010. Currently, he coordinates the Recognized Research Group "Electrical Characterization of Electronic Materials and Devices" of the University of Valladolid.

The main objective of our research group is the adaptation and fine-tuning to structures of a set of standard techniques based on the analysis of conduction mechanisms and electrical parameters (capacity, conductance, etc.). In addition, we have developed and extensively used original techniques and new variants of these standard techniques that are more precise and appropriate in certain circumstances.

Our scientific interest has focused in recent years on the study of high permittivity dielectrics in a double aspect: on the one hand, in the search for an alternative material to silicon dioxide as a gate insulator for integrated circuit transistors; on the other hand, in the development of applications in the field of memories, specifically those based on the resistive switching and ferroelectricity phenomena. Another point of interest for us is the use of graphene layers in combination con functional oxides layers. 